\title{
Mamíferos terrestres de la Región de Atacama, Chile. Comentarios sobre su distribución y estado de conservación
}

\section{Terrestrial mammals of the Atacama Region, Chile. Comments on Its distribution and conservation status}

\author{
Pablo Valladares Faúndez $\ddagger^{*}$ \\ ‡Departamento de Biología, Facultad de Ciencias, Universidad de Tarapacá. Velásquez 1775, Arica. pvalladares@uta.cl \\ *Centro Regional de Investigación y Desarrollo Sustentable de Atacama (CRIDESAT). Copayapu 485, Copiapó.
}

\begin{abstract}
RESUMEN
Se presenta una lista comentada de las especies de mamíferos terrestres de la Región de Atacama, Chile. Se analizó su distribución y estado de conservación a partir de datos de terreno, colecciones taxonómicas, literatura científica y reportes técnicos provenientes de instituciones públicas de Atacama. Se ha confirmado confirmado la presencia de 24 especies de mamíferos terrestres para la Región de Atacama, de las cuales el Orden más representativo es Rodentia, con 12 especies (50\%), seguido por Carnívora con 5 (20,8\%), Chiroptera con 3 (12,5\%), Artiodactyla con 2 (8,3\%) y Didelphimorphia con $2(8,3 \%)$. Sin embargo, se han mencionado otras 15 especies para Atacama, pero de las cuales no hay evidencias científicas. La determinación del estado de conservación de las especies tampoco es coincidente entre distintos métodos, y no representan necesariamente la situación local. Para cada una de las especies asignadas a Atacama se requiere mayor información sobre su abundancia local, distribución, presencia en las áreas silvestres protegidas, paisajes ecoregionales, características climáticas y geomorfológicas, así como en las distintas formaciones vegetacionales. Las zonas con mayor riqueza de especies son las Provincias de Huasco y Copiapó, en los valles transversales y costa. Sin embargo, se reconoce la falta de exploraciones científicas en gran parte de la región, particularmente el altiplano de la Provincia de Chañaral, donde otras especies pueden ser encontradas.
\end{abstract}

Palabras claVes: Mamíferos de Atacama, biodiversidad, conservación, distribución.

\begin{abstract}
Is present an annotated list of the terrestrial mammals species from the Atacama region, Chile. I analyse the distribution and conservation status based on field data, taxonomic collections, scientific, and technical reports from public institutions of Atacama. We have confirmed the presence of 24 species of terrestrial mammals, of which the most representative order is Rodentia, with 12 species (50\%), followed by Carnivora with 5 species (20,8\%), Chiroptera with 3 (12,5\%), Artiodactyla with $2(8,35 \%)$, and Didelphimorphia with $2(8,35 \%)$. However, there are 15 other species mentioned in Atacama but which there are not scientific evidence. The conservation status is not coincident among different methods and it does not necessarily reflect the local situation. To each species assigned to the Atacama region further information is required about local abundance, distribution, presence in the protected areas, ecoregional landscape, climatic and geomorphological characteristics, and vegetation formations. Areas with the highest species richness are the provinces of Huasco and Copiapó, in the transverse valleys and coastline. However, we recognize the lack of scientific exploration in much of the region, particularly the highlands of the Province of Chañaral, where other species could be found.
\end{abstract}

KEYWORDS: Mammals of Atacama, biodiversity, conservation, distribution.

\section{INTRODUCCIÓN}

La elaboración de un listado de especies puede tener como finalidad analizar el estado del conocimiento de un grupo taxonómico particular o de un área geográfica. De esa manera se busca evaluar la riqueza de especies, el nivel de endemismo y/o el grado de amenaza que existe sobre ellas (Elgueta et al. 2006). Por otro lado, los listados permiten identificar las áreas geográficas con interés de conservación (Simonetti 1999), nivel de exploración (Valladares 2011), y sirven de base para registrar y monitorear estacional y/o anualmente a las especies (Rau 2005). 
Los listados de mamíferos en Chile han sido esporádicos pero constantes en el tiempo. El primero de ellos lo realizó el Abate Juan Ignacio Molina (1782), muchas de las especies que describió aún son válidos y reconocidos por la comunidad de mastozoólogos. Otros naturalistas connotados que contribuyeron al desarrollo de la historia natural de los mamíferos chilenos fueron Gay y Philippi. Pasó casi un siglo para que otros naturalistas sistematizaran, sintetizaran y analizaran la información de mamíferos de Chile. De ellos, se deben destacar a Osgood (1943), Mann (1978), Tamayo \& Frassinetti (1980), Iriarte (2008) y Muñoz-Pedreros \& Yáñez (2000, 2009). Los listados de especies propuestos por estos autores, así como su distribución y estado de conservación, no han sido coincidentes para la mayoría de las especies, particularmente entre los dos últimos autores, lo que refleja una falta de información relevante en la mastozoología chilena. Por ello, es importante comenzar a desarrollar listados de especies a nivel regional, para determinar así cuales son los vacíos de conocimiento y definir con más certeza el estado de conservación de cada especie.

El nivel de conocimiento de la biodiversidad de la Región de Atacama, Chile, es escaso (Comité Nacional de Biodiversidad, en Simonetti et al. 1995), lo que ha quedado establecido, por ejemplo, en los lagartos (Valladares 2011). Por lo tanto, no es de extrañar que no se haya realizado un análisis crítico sobre el estado del conocimiento, la riqueza de especies ni el estado de conservación de los mamíferos de esta región. Este estudio tiene como objetivo entregar una lista comentada de los mamíferos de la Región de Atacama, Chile, y analizar el nivel de conocimiento y estado de conservación de dichas especies.

\section{MATERIAL Y MÉTODO}

La elaboración del listado de especies de mamíferos para Atacama se desarrolló a partir de la recolección y análisis de la información científica publicada en revistas nacionales e internacionales. En una primera instancia se tomó como referencia el listado de trabajos científicos publicados en diversas revistas científicas nacionales e internacionales que se encuentran en la página web (Silva - Aránguiz 2011). Para efectos de la estimación de la riqueza de especies y rangos de distribución en la región se consideraron además los textos de Osgood (1943), Mann (1978), Tamayo \& Frassinetti (1980), Galaz \&
Yáñez (2006), Iriarte (2008) y Muñoz-Pedreros \& Yáñez (2000, 2009). Esta información fue complementada con los planes de manejo de las áreas silvestres protegidas de Atacama, e incorporamos nuevas observaciones de terreno e información proveniente de colecciones taxonómicas de referencias, tanto nacionales como internacionales (CZZAUTA: Colección Zoológica de Zonas Áridas, Universidad de Tarapacá, Chile; MSB: Museum of Southwestern Biology, USA; MVZ: Museum of Vertebrate Zoology of the University of California at Berkeley, USA; FMNH: Field Museum of Natural History, USA; LCM: Laboratorio de Citogenética Evolutiva de Mamíferos de la Universidad de Chile; IEEUACH: Colección de Mamíferos de la Universidad Austral de Chile). Esta información permitió en algunos casos asignar las especies a ciertos patrones ecogeográficos, geomorfológicos y climas regionales, así como a formaciones vegetacionales determinados para Atacama por Juliá et al. (2008) y Novoa et al. (2008). Para cada especie asignada a la Región de Atacama se hizo una búsqueda en el ISI Web of Science, registrándose los artículos que analizaron alguna variable biológica de dichas especies para especímenes provenientes de la Región de Atacama.

\section{RESULTADOS}

A partir de la información recopilada, se pudieron asignar 24 especies de mamíferos terrestres para la Región de Atacama. Sin embargo, de acuerdo a Tamayo \& Frassinetti (1980), Galaz \& Yáñez (2006), Iriarte (2008) y Muñoz Pedreros \& Yáñez $(2000,2009)$, hay otras 15 especies que podrían encontrarse en la región, de las cuales no existen registros fidedignos, o bien habitan lugares aledaños y con ambientes similares en otras regiones de Chile y Argentina.

De las especies confirmadas para Atacama, existen 5 órdenes, 12 familias y 20 géneros. El Orden más representativo es Rodentia, con 5 familias, 10 géneros y 12 especies (54,5\%), seguido por Carnívora con 3 familias, 4 géneros y 5 especies (22,7\%). Posteriormente Chiroptera con 2 familias, 3 géneros y 3 especies (13,6\%). La Familia mejor representada es Cricetidae, con 6 especies. De los 20 géneros presentes, 15 son monotípicos.

Especies adscritas a la Región de Atacama. El listado de mamíferos para la Región de Atacama ha evolucionado considerablemente en los últimos 70 años (ver Tablas 1, 2 y 3). A continuación se presentan las especies de las cuales se tienen registros de su presencia en la Región de Atacama. 


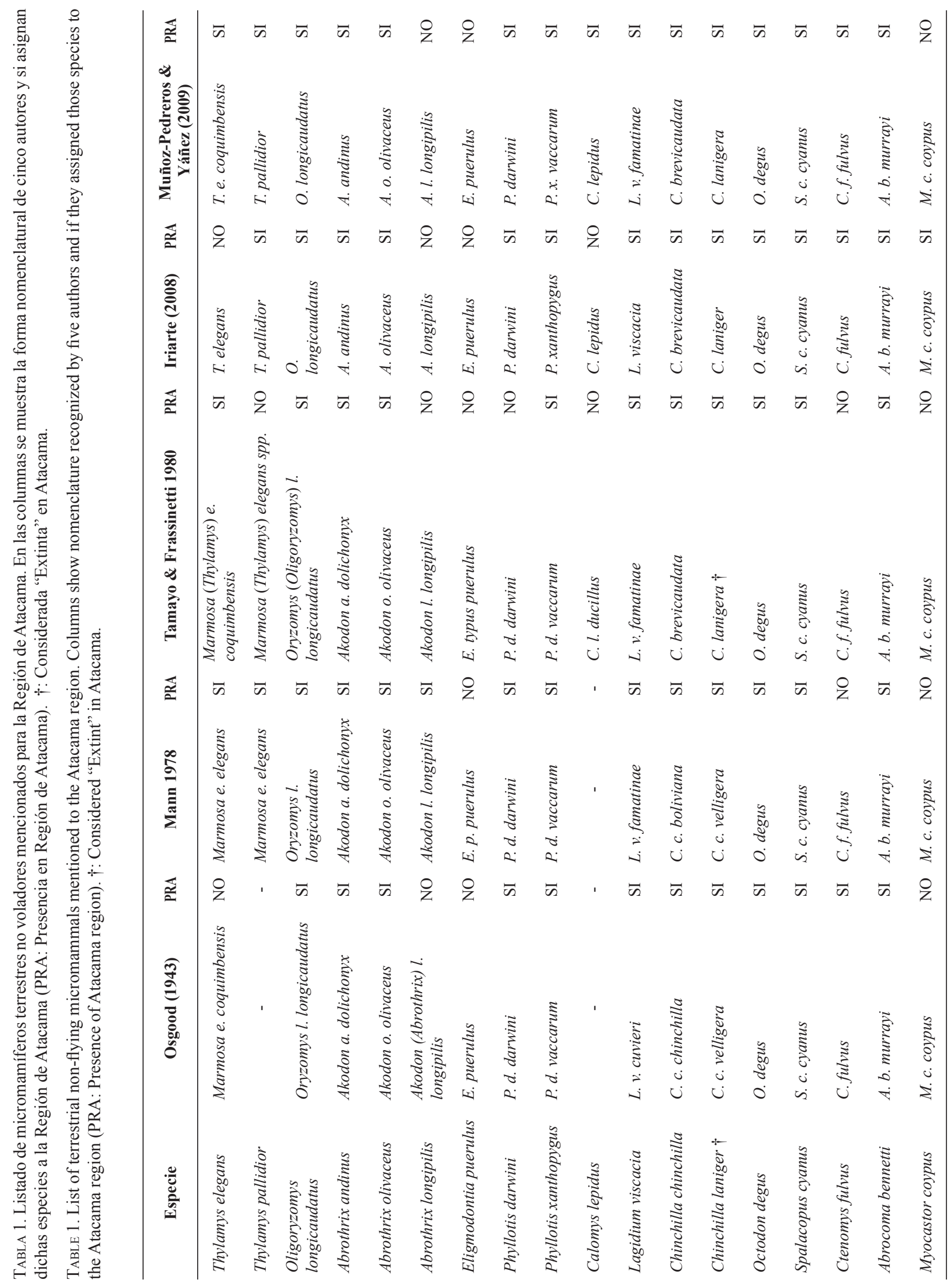




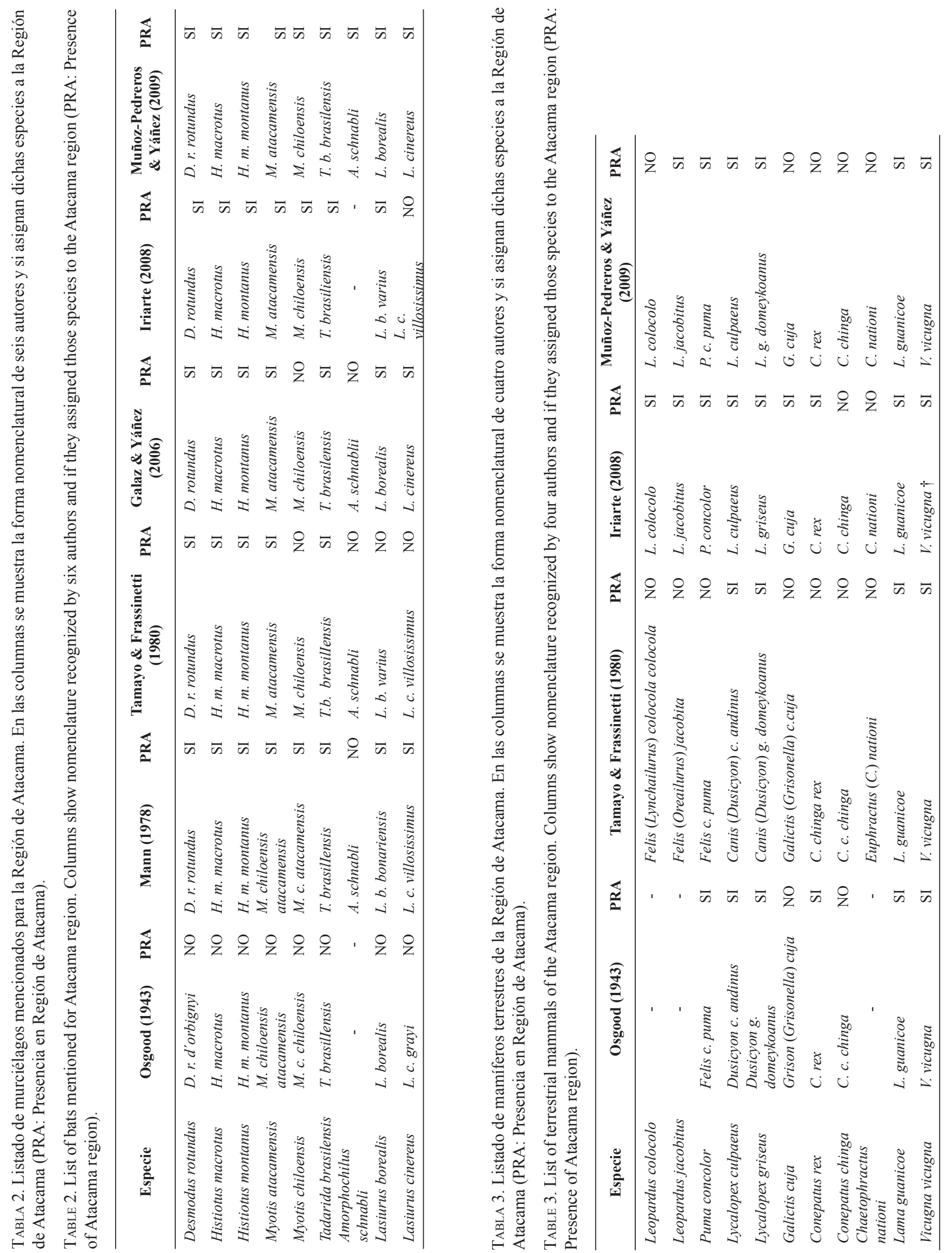




\section{DIDELPHIMORPHIA}

\section{Didelphidae}

Thylamys elegans (Waterhouse 1839)

"Yaca o Llaca"

Distribución: Es un marsupial con amplia distribución en Chile. Algunos autores determinan su distribución desde Coquimbo hasta Concepción (Osgood 1943, Iriarte 2008). Sin embargo, Muñoz-Pedreros \& Palma (2009) afirman que la subespecies $T$. e. coquimbensis habita en los valles transversales de Atacama y Coquimbo. Por otro lado, Mann (1978) y Tamayo \& Frassinetti (1980) afirma que T. e. elegans se distribuye desde Tarapacá hasta el Biobío por la costa. Registros en Atacama: En Atacama es registrada en Caldera y Vallenar por Muñoz-Pedreros \& Palma (2009). Hemos podido colectarla en la Quebrada El León, al norte de Caldera (CZZA-UTA 252). Al parecer, su distribución está restringida a quebradas de la Cordillera de la Costa a lo largo de toda la Región de Atacama, y valles transversales, no sobrepasando los $2000 \mathrm{~m}$.

Thylamys pallidor (Thomas 1902)

"Llaca de la puna"

Distribución: Comprende la precordillera y Puna andina (Palma 1997, Meynard et al. 2002).

Registros en Atacama: Palma (1995) encuentra un ejemplar depositado en el Smithsonian Institution (USNM 391776) colectado en la Mina Altamira, a la costa de Vallenar, y determinado como T. pallidor, aunque por su localidad de captura, es altamente probable que corresponda a T. elegans información que debe ser evaluada. Es asignada a Atacama por Muñoz-Pedreros \& Palma (2009).

\section{RODENTIA}

\section{Cricetidae}

Oligoryzomys longicaudatus (Bennett 1832)

"Colilargo"

Distribución: Esta especie puede ser encontrada desde la Región de Atacama hasta los bosques lluviosos de la XI Región de Chile (Muñoz-Pedreros \& Gil 2009, Mann 1978) e incluso Tierra del Fuego (Iriarte 2008). Generalmente se encuentra ligada a cursos de agua y zonas con alta cobertura vegetal.

Registros en Atacama: Ha sido colectada en la localidad de Piedra Colgada, en la Provincia de Copiapó (CZZA-UTA 250, 253, 301). Existen cinco ejemplares colectados en Ramadilla (FMNH 22660, 22661, 22662, 22663, 22664) y cuatro provenientes del PN Llanos de Challe (MSB 207294, 207295, 207296, 207297). También ha sido colectada al borde del Río Huasco, cerca de Freirina por el autor. Su distribución estaría restringida a los valles transversales de las Provincia de Huasco y Copiapó, particularmente en las desembocaduras de los ríos de esos mismos nombres.
Abrothrix andinus (Philippi 1858)

"Ratón andino"

Distribución: Su distribución está restringida a la Cordillera de Los Andes, desde la Puna de Perú, Bolivia, Argentina y Chile, hasta los $34^{\circ} \mathrm{S}$ aproximadamente (Iriarte 2008, Muñoz-Pedreros \& Gil 2009).

Registros en Atacama: En Atacama la hemos colectado en el Parque Nacional Nevado Tres Cruces, entre rodados y quebradas (CZZA-UTA 266, 305). Se han colectado especimenes asignados a esta especie muy cerca de la Región de Atacama, en el Observatorio La Silla (IV Región) (MSB 210219) y en Argentina (MSB 141303).

Abrothrix olivaceus (Waterhouse 1837)

"Ratón oliváceo"

Distribución: Tiene gran distribución en Chile, desde la Región de Arica-Parinacota hasta Magallanes (MuñozPedreros \& Gil 2009). En el norte existen dos subespecies, una de ellas, A. o. olivaceus se encontraría en Atacama (Rodríguez-Serrano et al. 2006).

Registros en Atacama: Ha sido colectada en Caldera (Meserve \& Glanz 1978), existe un espécimen proveniente del norte de Caldera (MVZ 150052), otros cinco provenientes de Ramadilla, Copiapó (FMNH 230005, 23006, 23007, 23008, 23009) y cinco de la Quebrada Pajonales, $22 \mathrm{~km}$ al norte de Caldera(FMNH 132344, 132341, 132342, 132343, 132345), varios ejemplares proveniente del P. N. Llanos de Challe y P.N. Pan de Azúcar (MSB 207149, 207150, 207152, 207153, 207155 - 207162, 206882 - 206884, 206886 - 206889, 206891 - 206895, 230003, 230034, 230035, 230042, 230048, 230049, 230181, 230307). La hemos colectado en la Quebrada El León (CZZA-UTA 255, 331), Obispito (CZZA-UTA 310 - 316), Piedra Colgada (CZZA-UTA 251) y Copiapó (CZZA-UTA 300). Su distribución en Atacama es principalmente por el borde costero y valles transversales de las Provincias de Huasco y Copiapó, no sobrepasando los $2000 \mathrm{~m}$.

\section{Eligmodontia puerulus (Philippi 1896)}

"Ratón de pie sedoso"

Distribución: Su distribución estaría restringida a la puna de Bolivia, Argentina y Chile (Mares et al. 2008, Iriarte 2008; Muñoz-Pedreros \& Gil 2009). Su rango de distribución sur correspondería hasta la Región de Antofagasta (Mann 1978).

Registros en Atacama: Se han colectado especimenes de este género en los alrededores de Copiapó (sector Barranquilla al sur), y en la franja costera de la Provincia de Copiapó (CZZA-UTA 268, 050 - 056, 317 - 320). Su distribución en Atacama sería el Altiplano, particularmente a los alrededores del Parque Nacional Nevado Tres Cruces, precordillera y valles transversales. 
Phyllotis darwini (Waterhouse 1837)

"Ratón orejudo de Darwin"

Distribución: Presenta una amplia distribución en Chile, siempre ligada al cordón montañoso costero, desde la Región de Antofagasta hasta la Región de la Araucanía (Iriarte 2008, Muñoz-Pedreros \& Gil 2009).

Registros en Atacama: Ha sido colectada desde el Parque Nacional Pan de Azúcar (MSB 206885, 207151, 230036), norte de Caldera (MVZ 150056), hasta el Parque Nacional Llanos de Challe (MSB 223994, 207154, LCM 2511) y Vallenar (MVZ 150057, 118658, 118659). También fue colectado en Caldera y Vallenar por Meserve \& Glanz (1978). En la Colección de Mamíferos de la Universidad Austral de Chile se encuentran ejemplares colectados en Carrizal Bajo (IEEUACH 3267, 3268, 3269, 3270, 3271, 3272). En nuestra colección se encuentran ejemplares colectados en el P.N. Pan de Azúcar (CZZA-UTA 333, 339), Quebrada El León (CZZA-UTA 254, 335) y Puerto Fino, al sur de Chañaral (CZZA-UTA 336, 340) y en la ciudad de Copiapó (CZZA-UTA 334). Su distribución en Atacama estaría restringida al cordón montañoso de la Cordillera de la Costa, desde Chañaral hasta el extremo sur de Huasco, y en los cordones montañosos que acompañan los valles transversales.

Phyllotis xanthopygus (Waterhouse 1837)

"Ratón orejudo amarillento"

Distribución: Muñoz-Pedreros \& Gil (2009) la restringen a la patagonia argentino-chilena y no mencionan ninguna especie de este género para el cordón andino de Atacama. Para Iriarte (2008) efectivamente esta especie habita en el cordón andino de Atacama, llegando hasta el extremo norte de Chile. Es considerada muy divergente de $P$. darwini por Steppan et al. (2007).

Registros en Atacama: Los antecedentes de colectas para Atacama son escasos, se encuentran registros en la frontera con Argentina (MVZ 141510, 141511, 141512), al sur de Atacama, en Domeyko (FMNH 22339 y 22340) y en el Parque Nacional Nevado Tres Cruces (CZZA-UTA 267, 306 - 309). En Atacama su distribución es la puna atacameña y cordillera de Los Andes de la Provincia de Huasco.

\section{Chinchillidae}

Chinchilla chinchilla (Lichtenstein 1829)

"Chinchilla de cola corta o altiplánica"

Distribución: Se le ha asignado una amplia distribución geográfica (Iriarte 2008, Muñoz-Pedreros \& Gil 2009), sin embargo, se han podido identificar sólo dos colonias de esta especie en la Región de Antofagasta (Spotorno et al. 2004). Registros en Atacama: Los registros de chinchilla en la Región de Atacama son escasos, mal documentados y poco recientes (Valladares et al. En Prensa). Recientemente, estos autores reportaron dos nuevos hallazgos de esta especie en el Parque Nacional Nevado Tres Cruces y sus alrededores, cerca de $4000 \mathrm{~m}$. Se tiene información de la presencia de esta especie en las provincias de Chañaral y Huasco, las que deben ser confirmadas.

Lagidium viscacia (Molina 1782)

"Vizcacha"

Distribución: Presenta una amplia distribución geográfica, la que algunos autores subdividen en varias subespecies (Wilson \& Reeder 2005; Iriarte 2008; Muñoz-Pedreros \& Gil 2009) y otros la han definido en estatus específicos (Anderson 1997). Sin embargo, no hay consenso cuál de ellas habitaría la Región de Atacama, ya que para algunos autores correspondería al límite de la distribución entre $L$. peruanum y L. viscacia (ver Tabla 2).

Registros en Atacama: Sus colectas son muy escasas, podemos encontrar en Spotorno et al. (2004) un ejemplar colectado en la Laguna Santa Rosa (LCM 2359), Provincia de Copiapó. Sin embargo, son frecuentes los avistamientos de esta especie en las cercanías del Salar de Pedernales (ca. $26^{\circ} 23^{\prime} 41.59^{\prime \prime} \mathrm{S}$; $68^{\circ} 51^{\prime} 08.12^{\prime \prime} \mathrm{O}$ ), altiplano de la Provincia de Copiapó y en Los Andes de la Provincia de Huasco.

\section{Octodontidae}

Octodon degus (Molina 1782)

"Degú"

Distribución: Tiene una amplia distribución, desde la Provincia de Huasco (Osgood 1943) hasta Curicó (Mann 1978).

Registros en Atacama: Efectivamente, se han colectado especimenes en la Hacienda Atacama $\left(28^{\circ} 30^{\prime} 39,28^{\prime \prime} \mathrm{S}\right.$; $71^{\circ} 01^{\prime} 01.45^{\prime \prime} \mathrm{O}$ ), muy cerca de Freirina (Valladares 2009). Sin embargo, parece que esta población está estrictamente restringida a una pequeña quebrada, pues no fue posible colectarla en otros lugares aledaños. Hay cuatro individuos colectados en Vallenar (FMNH 24051, 23200, 23201 y 23202). Porter (1899) menciona para la Provincia de Atacama a Octodon cummingii en los cerros de San Antonio, localidad cercana a Los Loros, actual Provincia de Copiapó, lo que correspondería a la localidad más al norte para la especie.

\section{Spalacopus cyanus (Molina 1782)}

"Cururo"

Distribución: Su rango de distribución comienza en la Provincia de Copiapó, por la costa, hasta el Maule (Osgood 1943).

Registros en Atacama: Los avistamientos de curureras habitadas y activas son frecuentes en el Parque Nacional Llanos de Challe. Se observan además curureras en la Quebrada de El León y alrededores de Caldera, pero no se tienen registros de colectas en colecciones de referencia. Las poblaciones del extremo norte de su distribución son atribuidas a la subespecie S. c. cyanus (Osgood 1943). 


\section{Abrocomidae}

Abrocoma bennetti (Waterhouse 1837)

"Ratón chinchilla"

Distribución: con una amplia distribución en Chile, desde el Valle de Huasco hasta el borde norte del Río Itata, VIII Región (Muñoz-Pedreros \& Gil 2009).

Registros en Atacama: Es conocido por su pelaje suave y color similar a la chinchilla costina. Se distinguen dos subespecies, A. b. murrayi para las regiones de Atacama y Coquimbo, y $A$. $b$. bennetti para el resto del país (Osgood 1943, Muñoz-Pedreros \& Gil 2009). Wolffsohn (1916) describió A. murrayi como nueva especie, el que fue colectado en Vallenar: Se considera que esta subespecie tendría una distribución entre Vallenar (III Región) y Coquimbo (IV Región). Existen cuatro pieles de esta subespecie colectados en Huasco (FMNH 23169, 2317 y 23171) y en la localidad de Domeyko (FMNH 23172) por C. Sanborn. Wolffsohn (1923) menciona cuatro machos y tres hembras capturados en Vallenar, por sir John Murray. Recientemente, se colectaron especimenes de $A$. $b$. murrayi en la Provincia de Copiapó, específicamente en la localidad de Piedra Colgada ( $\left.27^{\circ} 18^{\prime} 00^{\prime \prime} \mathrm{S}, 70^{\circ} 29^{\prime} 00^{\prime \prime} \mathrm{O}\right)$. Estas poblaciones tienen preferencias por grandes matas de Atriplex, sin embargo no hemos podido lograr nuevas colectas, ya que las poblaciones de Rattus en dicho lugar son muy abundantes.

\section{Ctenomidae}

\section{Ctenomys fulvus Philippi 1860}

"Chululo"

Distribución: De acuerdo a Muñoz-Pedreros \& Gil (2009) e Iriarte (2008), habita en la puna de Bolivia, Argentina y Chile, teniendo una distribución desde la Provincia de Arica - Parinacota hasta la Provincia de Vallenar.

Registros en Atacama: Muñoz-Pedreros \& Gil (2009) e Iriarte (2008) la citan para Atacama, pero no hemos obtenido información de localidades específica de colectas. Sin embargo, es frecuentemente citada en informes técnicos ambientales. Hemos podido observar "chululeras" activas en varias partes del altiplano atacameño, como en La Ola en el sector del Salar de Pedernales, o en Parque Nacional Nevado Tres Cruces, con cavidades recientemente removidas, pero no tenemos registros de colectas de especimenes en colecciones de referencia.

\section{CHIROPTERA}

\section{Phyllostomidae}

Desmodus rotundus (E. Geoffroy 1810)

"Piuchén, Vampiro"

Distribución: Presenta una amplia distribución en América, que va desde México hasta Chile, Argentina, Paraguay, Uruguay y Brasil. En Chile se encuentra desde Arica hasta Coquimbo (Galaz \& Yáñez 2006). Se le reconocen tres subespecies, siendo D. r. rotondus habitante de Chile.

Registros en Atacama: En Atacama se le registra en el Parque Nacional Pan de Azúcar (CONAF 2002), donde se le encuentra entre quebradas, y particularmente se tiene registrada una colonia en la Isla Pan de Azúcar. Además acaba de ser registrada una colonia en la Reserva Nacional Pingüino de Humbolt, en la Isla Chañaral de Aceituno.

\section{Vespertilionidae}

Histiotus macrotus (Poeppig 1835)

"Murciélago orejudo mayor"

Distribución: Tiene una amplia distribución en América del Sur. En Chile, desde la Región de Arica-Parinacota hasta el sur de Concepción, a lo largo de la costa (Iriarte 2008, Galaz et al. 2009).

Registros en Atacama: Galaz \& Yáñez (2006) reportan una colonia para la zona costera de la Provincia de Chañaral.

Myotis atacamensis (Lataste 1892)

"Murciélago de Atacama"

Distribución: es considerado el murciélago más pequeño del género. Se caracteriza por tener el cuerpo cubierto con un pelo largo, amarillento por el dorso y más pálido en el vientre (Cabrera 1903). Su distribución es desde el sur de Perú hasta el valle de Elqui (Galaz \& Yáñez 2006).

Registros en Atacama: En Atacama ha sido colectada en Caldera por Enrique E. Gigoux y entregado para su estudio a Ángel Cabrera, quién lo incluyó en su Catálogo de 1903. Además está descrito para el P.N. Pan de Azúcar (CONAF 2002). Tenemos un registro de esta especie en Piedra Colgada, 15 kilómetros al poniente de Copiapó (CZZAUTA 600, 601).

\section{CARNIVORA}

\section{Felidae}

Leopardus colocolo (Molina 1782)

"Gato Colocolo"

Distribución: Desde Ecuador y Brasil, hasta la Patagonia de Chile y Argentina. En Chile se encontraría desde Coquimbo hasta Magallanes, y desde el nivel del mar hasta el altiplano (Osgood 1943, Quintana et al. 2009).

Registros en Atacama: Se reconoce para la Región de Atacama sólo en el altiplano (Iriarte 2008). Gigoux (1926) relata haber visto una piel fresca de "gato montés" o equivocadamente llamado Felis guigna, cazado en la Quebrada El León en 1902. Según se decía, era muy común en la zona, pero ya en esas décadas había comenzado a desaparecer. Tuvo la oportunidad de ver a otro ejemplar de iguales características, cazado en 1924 en "Tres Quebradas". Gigoux (1939) menciona la presencia de Felis pajeros para la zona conocida como "La Travesía", valle central entre Vallenar y Copiapó. Es posible que se tratara de L. colocolo. No existen ejemplares en colecciones de referencia 
provenientes de la Región de Atacama.

Puma concolor (Linneus 1771)

"Puma"

Distribución: Tiene una amplia distribución en América, actualmente se reconocen seis subespecies, siendo P. c. puma residente de Chile. Habita desde el nivel del mar hasta sobre los $4000 \mathrm{~m}$ y desde zonas desérticas a bosques lluviosos tropicales (Currier 1983). Esta especie está ampliamente distribuida en Chile, desde Parinacota al sur de la península de Brunswick, Provincia de Magallanes (Villalobos 2008, Franklin et al. 1999).

Registros en Atacama: En Atacama tiene una amplia distribución abarcando desde el nivel del mar hasta el altiplano, y desde la Provincia de Chañaral hasta la de Huasco. En el altiplano, se encuentran registros en el Salar de Pedernales y Laguna Verde (Grimberg et al. En Prensa). En el Parque Nacional Nevado Tres Cruces se encuentran frecuentemente vicuñas cazadas por pumas. Gigoux (1926) afirma que en la Quebrada El León era una "morada predilecta de ellos o residencia temporal preferida que les ofrecía alimento y refugio seguros" y continúa "El último que tengo conocimiento fue cazado en el "Veladero", punto de la costa al sur de Caldera, por José Félix Reyes y Antonio Aracena, en Mayo 6 de 1913" ..... "Después oí decir se habían visto a algunos merodear por el Morro Copiapó y Quebrada El León”. Gigoux (1939) también afirma que en "La Travesía" solían bajar pumas para cazar ganado, pero que sin embargo, hace mucho no se les veía por la zona.

\section{Canidae}

Lycalopex culpaeus (Molina 1782)

"Zorro culpeo"

Distribución: Se encuentra en todo Chile (Quintana et al. 2009),

Registros en Atacama: En Atacama ocupa ambientes altiplánicos, valles centrales y costeros. Se observa frecuentemente en los parques nacionales Nevado Tres Cruces, Llanos de Challe y Pan de Azúcar. Hemos encontrado especimenes atropellados cerca de Chañaral y cerca de El Salvador.

Lycalopex griseus (Gray 1837)

"Zorro gris o Chilla"

Distribución: Su distribución es amplia, desde Arica hasta Magallanes (Osgood 1943, Iriarte 2008, Quintana et al. 2009).

Registros en Atacama: Phillipi (1901) describe a Canis domeykoanus con Terra typica en la Provincia de Copiapó. Posteriormente es colocado en categoría de subespecie, como L. g. domeykoanus (Osgood 1943). En Atacama parece estar solamente en los valles centrales y costeros, pero no se observa en el altiplano. Osgood (1943) revisa pieles provenientes de Domeyko, Atacama, en el Field Museum of Natural History. Se ha encontrado un espécimen atropellado en las cercanías de Piedra Colgada, $15 \mathrm{kms}$ al poniente de Copiapó.

\section{Mephitidae}

Conepatus chinga (Molina 1782)

"Chingue común"

Distribución: Se distribuye desde Coquimbo hasta Osorno (Osgood 1943, Iriarte 2008).

Registros en Atacama: Si bien no ha sido registrada científicamente para Atacama, existen varias observaciones que la acreditan en este listado. En primer término, Gigoux (1926) relata que un viejo leñador de la Quebrada El León le decía haber visto chingues en ese lugar, y dice "...los detalles que me daba de la defensa característica del animal y de su pelaje coincidían con la realidad". Por otro lado ha sido observado en el Parque Nacional Llanos de Challe (CONAF 1997a).

\section{ARTIODACTYLA}

\section{Camelidae}

Lama guanicoe (Müller 1776)

"Guanaco"

Distribución: Tiene una amplia distribución altoandina, desde Perú y Bolivia, hasta la Patagonia de Chile y Argentina, incluyendo Tierra del Fuego e Isla Navarino (González et al. 2006).

Registros en Atacama: En Atacama presentan una amplia distribución, desde el altiplano hasta el nivel del Mar. Se observan tropillas en la Provincia de Chañaral, en el Salar de Pedernales y en el Parque Nacional Pan de Azúcar. Hemos observado una tropilla pequeña en quebradas interiores

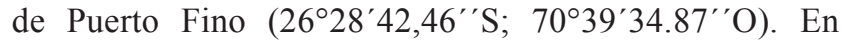
la Provincia de Copiapó se observan en el sector de la Laguna del Negro Francisco y Parque Nacional Nevado Tres Cruces, Río Jorquera y alrededores de Totoralillo. En la Provincia de Huasco, se observan en el PN Llanos de Challe. Gigoux (1939) la menciona para el sector de "La Travesía", y en 1926 relata que fueron comunes en la Quebrada El León, donde era frecuente encontrarla en tropillas de seis ejemplares, pero los últimos fueron cazados en 1915, y desde entonces no se han vuelto a ver en la zona. Marín et al. (2008) analizan la variabilidad genética de las distintas poblaciones y subespecies de esta especie, considerando a las poblaciones atacameñas como L. g. huanacus, y obteniendo muestras de tejido de especímenes provenientes de P.N. Pan de Azúcar $\left(26^{\circ} 06^{\prime} \mathrm{S}\right.$, $\left.70^{\circ} 38^{\prime} \mathrm{O}\right)$, P.N. Llanos de Challe $\left(28^{\circ} 10^{\prime} \mathrm{S}, 71^{\circ} 05^{\prime} \mathrm{O}\right)$, Huasco $\left(28^{\circ} 31^{\prime} \mathrm{S}, 70^{\circ} 56^{\prime} \mathrm{O}\right)$ y Alto del Carmen $\left(28^{\circ} 31^{\prime} \mathrm{S}\right.$, $70^{\circ} 56^{\prime} \mathrm{O}$ ). 
Vicugna vicugna (Molina 1782)

"Vicuña"

Distribución: Tiene una distribución restringida al altiplano de Perú, Bolivia, Argentina y Chile. En Chile, esta especie está distribuida desde la Región de Arica y Parinacota, hasta la Región de Atacama.

Registros en Atacama: Es frecuentemente observada en los alrededores del Salar de Pedernales, en el sector del P.N. Nevado Tres Cruces, Laguna del Negro Francisco y Laguna Santa Rosa. Marín et al. (2007) evalúa el origen de la domesticación de Lama glama y Lama pacos, con marcadores moleculares y citogenéticos, colectando especímenes de $V$. vicugna en el P. N. Nevado Tres Cruces.

Existen otras especies que han sido mencionadas para la Región de Atacama, y de la cuales no existen registros científicos fidedignos, tales como Abrothrix l. longipilis (Waterhouse 1837), que es indicada en el mapa de distribución para el sur de la Región de Atacama y Calomys lepidus (Thomas 1884) para el extremo norte de la Región (Muñoz-Pedreros \& Gil 2009); En el caso de los murciélagos, Histiotus montanus (Philippi \& Landbeck 1861), Lasiurus borealis (Müller 1776) y Lasiurus cinereus (Palisot de Beauvois 1796) son asignados para Atacama por Galaz \& Yáñez (2006); Myotis chiloensis (Waterhouse 1840) por Iriarte (2008) y Galaz et al. (2009); Tadarida brasilensis (Geoffroy 1824) por Galaz \& Yáñez (2006), Galaz et al. (2009) e Iriarte (2008) y Amorphochilus schnabli Peters 1877 es asignado a Atacama por Galaz et al. (2009). En el caso de los carnívoros, Leopardus jacobitus (Cornalia 1865) es asignado para Atacama por Iriarte (2008) y Quintana et al. (2009), así como Galictis cuja (Molina 1782) por Iriarte (2008); Conepatus rex (Thomas 1898) por Iriarte (2008) y finalmente Chaetophractus nationi (Thomas 1894) por Tamayo (2009). Tanto Abrocoma cinerea como Myocastor coypus no tienen registros de colectas ni referencias para la Región de Atacama, sin embargo, los límites de distribución que se les han asignado son cercanos a la Región de Atacama, y habitan lugares con características similares a las de esta región. Por último, Chinchilla laniger (Molina 1782) ha sido mencionada para la Región de Atacama. Grau (1986) afirma que tanto $C$. chinchilla como C. laniger (Molina 1782) habrían sido simpátricas en la localidad de Potrerillos, al este de El Salvador, Región de Atacama. Parece muy poco probable, pero al menos existen antecedentes de la presencia de $C$. laniger en Atacama bastante más al sur, en los alrededores de Vallenar (Wolffsohn 1921). Iriarte (2008) y Muñoz-Pedreros \& Gil (2009) la mencionan para Atacama, aunque sin dar mayores antecedentes. Esta especie se encuentra actualmente restringida a la Reserva Nacional Las Chinchillas, IV Región y existe un registro de un individuo colectado en la localidad de La Higuera, en el norte de la Región de Coquimbo (Valladares 2002, Spotorno et al. 2004). Debe prospectarse su posible presencia en la
Región de Atacama, particularmente en quebradas de la zona costera de la Provincia de Huasco, como por ejemplo en el Parque Nacional Llanos de Challe y alrededores, y también hacia la comuna de Alto del Carmen, Provincia de Huasco.

\section{Patrones de distribución y riqueza de especies de los} mamíferos de Atacama.

Es muy escasa la información sobre la distribución y abundancia de las especies de mamíferos atacameños. Hasta ahora su distribución no se ha relacionado con variables como formaciones vegetacionales, climas regionales, geomorfología y paisajes ecogeográficos. Esta información es muy útil para evaluar las prioridades de conservación de las especies de mamíferos a nivel regional.

De acuerdo a la información disponible, y de la certeza de 24 especies presentes en Atacama, se evaluó la presencia de estas en los distintos climas regionales, paisajes ecogeográficos, formaciones vegetacionales y geomorfología, buscando con ello determinar las zonas de mayor riqueza de especies.

En relación a los climas regionales, el Desierto Costero con Nubosidad Abundante se encuentra en la franja costera entre Chañaral $\left(26^{\circ} 21^{\prime} \mathrm{S}, 70^{\circ} 37^{\prime} \mathrm{O}\right)$ y Quebrada Los Choros (29²0’S) (Juliá et al. 2008). El aire costero de esta zona presenta altas nubosidades, con una Humedad Relativa del $74 \%$, lo que genera una vegetación permanente en la cordillera de la costa (Squeo et al. 2004). Esta zona es la que presenta el mayor porcentaje de especies de Atacama (62,5\%), donde destaca la presencia de P. darwini, A. olivaceus, T. elegans, L. culpaeus y L. griseus. Entre el límite de esta formación, y los $1500 \mathrm{~m}$ se desarrolla una zona árida, con precipitaciones invernales escasas y variables, denominado Clima Desértico Transicional. Esta zona también tiene alta riqueza de especies, con un $54,2 \%$ de las especies presentes en Atacama. Esta zona árida es poblada por roedores del género Eligmodontia, particularmente en las zonas de dunas. Según Köppen (1948), desde los $1500 \mathrm{~m}$ hasta los $4000 \mathrm{~m}$ se identifica un clima de desierto frío, donde las temperaturas son determinadas por la altura, denominado Clima de Desierto Frío de Montaña. En este ambiente se encuentra el 54,2\% de las especies, entre las que destacan L. guanicoe. Finalmente, sobre los $4000 \mathrm{~m}$ se encuentra el Clima de Tundra de Alta Montaña, caracterizado porque las fluctuaciones de temperatura están rondando el $0^{\circ} \mathrm{C}$, pero que en verano no alcanzan los $10^{\circ} \mathrm{C}$. Acá está representado el $50 \%$ de las especies atacameñas, cifra que podría variar si se considera que dicha zona podrían habitar otras especies, tales como T. pallidior, C. lepidus, A. cinerea, L. jacobitus, C. rex y C. nationi.

Las formaciones vegetacionales son muy heterogéneas en Atacama, las que dependen de las condiciones climáticas y topográficas (Novoa et al. 2008). Estos autores se inclinan 
por la determinación de Gajardo (1994), la que contiene 12 formaciones, de las cuales, nosotros incorporamos a nuestro análisis sólo 11, excluyendo Altas Cumbres Sin Vegetación. La formación vegetacional con mayor representación de mamíferos es Desierto Costero de Huasco, con el 62,5\% de las especies, seguido por el Desierto Florido de los Llanos con el 58,3\% de las especies, el Desierto Florido de las Serranías y la Estepa Desértica de los Salares Andino con un $50 \%$ de las especies. El Desierto Costero de Taltal está representado con un 45,8\% de las especies. Las formaciones vegetacionales con menor riqueza de especies parecen ser Desierto Interior de Taltal (16,7\%), Desierto Estepario de El Salvador (20,8\%), Desierto Montano de la Cordillera de Domeyko (25\%), Desierto Estepario de Sierras Costeras (25\%), Desierto Altoandino de los Ojos del Salado y Estepa Altoandina de la Cordillera de Doñana cada una con $37,5 \%$ de las especies.

En relación a las características geomorfológicas, Novoa et al. (2008) citan diez unidades para Atacama. En nuestro análisis excluimos Salares y Lagunas. De acuerdo a la mastofauna asociada a las ocho unidades restantes, la que presenta la mayor riqueza es la Cordillera de la Costa con un $62,5 \%$ de las especies, seguida por la unidad de Planicies Fluviométricas con un 58,3\%, Pampa Transicional y la Cordillera de Los Andes ambas con 54,2\% de las especies. En un nivel intermedio se encuentra la Cuenca Altiplánica con un 45,8\% de las especies y la Pampa Ondulada Austral con $37,5 \%$. Los menores valores se encuentran en la Precordillera de Domeyko y Cordillera de Domeyko con $25 \%$ respectivamente.

Los paisajes ecogeográficos de Atacama surgen producto de la integración de los parámetros antes descritos (Novoa et al. 2008). La mayor riqueza de especies de mamíferos se encuentran en las unidades denominadas Valles $(58,3 \%)$, Costa y Andina con un 54,2\% cada una. La unidad Serrano presenta un 48,5\% de las especies y Altiplánico un 50\%. Finalmente Pampeano y Preandino quedan representadas con $16,7 \%$ y $37,5 \%$ respectivamente.

Estado de Conservación de los mamíferos de Atacama. Se analizó el estado de conservación de las especies de mamíferos aquí asignadas para Atacama, a partir de los criterios de la IUCN (2011), Cartilla de Caza del Servicio Agrícola y Ganadero (SAG 2004), Corporación Nacional Forestal (CONAF 1993) y el Índice de Conservación Prioritaria de Cofré \& Marquet (1999), así como su presencia en las Áreas Silvestres Protegidas en Atacama y nivel de endemismo (Tabla 4). Cabe mencionar que para este listado se incluyó a la especie $C$. laniger dado que existe información fidedigna de su antigua existencia en la Región de Atacama.

En el caso de la IUCN, el 87,5\% de las especies fueron asignadas a "Preocupación Menor"; 1 especie (4,16\%) se encuentra "Críticamente Amenazada" y corresponde a C. chinchilla. Dos especies (8,3\%) son consideradas "Cercanamente Amenazadas" y presentan una información muy precaria para la Región de Atacama (M. atacamensis y L. colocolo).

En la categorización del SAG, el 53,9\% de las especies aparecen sin información, cerca del 18\% de las especies son "Raras" o "Inadecuadamente Conocidas". De las especies asignadas a "Vulnerable" (7,7\%), en ninguna de ellas se tiene certeza de su distribución en Atacama. El 20,5\% de las especies está "En Peligro", de las cuales seis de ellas se tiene certeza de su existencia en Atacama. Sin embargo, una de ellas, $P$. concolor, tiene una amplia distribución en la región (Grimberg et al. en prensa), aunque no se conoce su abundancia local. Entre las especies "En Peligro" aparecen los dos camélidos, Lama guanicoe y Vicugna vicugna.

En relación a la evaluación de la CONAF, el 45,8\% de las especies no tiene asignada una categoría de conservación, mientras que cinco especies $(20,83 \%)$ están catalogadas como "En Peligro", tres especies son consideradas como "Vulnerable" (12,5\%), otras tres como "Inadecuadamente Conocida" (12,5\%), una como "Rara" $(4,16 \%)$ y una como "Fuera de Peligro" (4,16\%).

El Índice de Conservación Prioritario (ICP) (Cofré \& Marquet 1999) es una metodología que considera, para cada especie, información de especificidad de hábitat, distribución geográfica en Chile, abundancia local, endemismo, singularidad taxonómica, masa corporal, presencia en otras listas, efecto antrópico y grado de protección. En 4 especies listadas acá no se desarrolló esta evaluación, de las cuales tres corresponden a murciélagos. Esto se debe a que el ICP de Cofré y Marquet (1999) fue calculado sólo para mamíferos terrestres no voladores. Ocho de las especies fueron catalogas como "Sin Prioridad Inmediata" (33,3\%), entre ellas las dos especies de Thylamys, O. longicaudatus, A. olivaceus, P. xanthopygus y L. culpaeus, C. chinga, C. fulvus y $A$. longipilis. Cinco de las especies resultaron ser adscrita a la categoría de "Frágil" (20,83\%) y cuatro a "Vulnerable" (16,6\%). Dos especies con catalogadas "En Peligro" (8,33\%) y una "Crítica" $(4,16 \%)$. La única especie en la que coinciden las cuatro listas es $C$. chinchilla, la que es considerada En Peligro, Crítica o Críticamente Amenazada. Existe además una alta coincidencia entre los listados de CONAF y SAG, coincidiendo en 9 de las 24 especies.

Diecinueve de las 24 especies que habitan en la Región de Atacama (79,16\%) se encuentran mencionadas para algunas de las Áreas Silvestres Protegidas. Solo L. guanicoe y L. culpaeus se encuentran en los tres parques nacionales de la región. $T$. elegans, A. olivaceus, $P$. darwini y L. griseus se encuentran en 


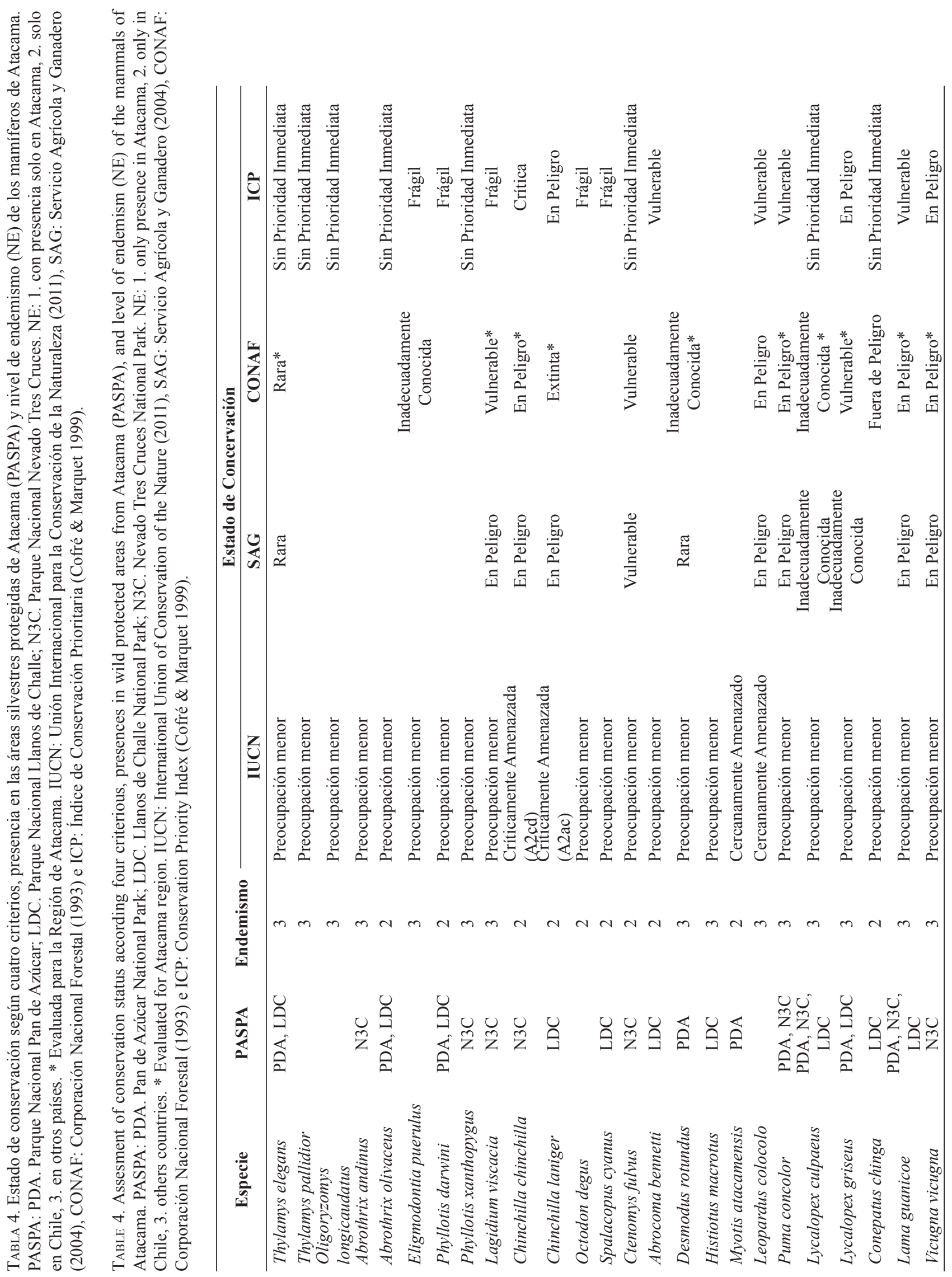


los dos parques nacionales costeros, mientras que $A$. andinus, $P$. xanthopygus, C. fulvus, L. viscacia, C. chinchilla y $V$. vicugna se encuentran protegidos solo en el P.N. Nevado Tres Cruces. En el P.N. Llanos de Challe se encuentran protegidas S. cyanus, $A$. bennetti, H. macrotus y C. chinga, y en el P.N. Pan de Azúcar $M$. atacamensis y $D$. rotondus. Parece dudosa la presencia de C. laniger en Llanos de Challe (CONAF 1997a, 1997b, 2002). El parque nacional que contiene la mayor cantidad de especies de mamíferos sería Llanos de Challe, con 10 especies, seguido de Pan de Azúcar y Nevado Tres Cruces, ambas con nueve especies.

El nivel de endemismo de los mamíferos de Atacama es nulo. De las 24 especies confirmadas, ninguna tiene una distribución restringida a la Región de Atacama. Del total de especies, el 37,5\% es endémico de Chile, y el 25\% habita sólo en la macrozona norte.

\section{DISCUSIÓN}

La discusión se centrará en el nivel de conocimiento de los mamíferos atacameños, así como el estado de conservación de las 24 especies asignadas para Atacama, pero en un contexto local, ya que existen diferencias sustanciales entre las distintas listas de conservación analizadas. Finalmente, se discuten algunas consideraciones taxonómicas de algunas especies.

En términos de nivel de conocimiento, se ha podido constatar que el listado de especies de mamíferos para Atacama no está completamente definido. Se han realizado algunos listados de especies a nivel nacional, en los cuales queda de manifiesto importantes contradicciones en lo que concierne a Atacama, pues los rangos de distribución no coinciden para muchas de las especies (Galaz \& Yáñez 2006, Iriarte 2008, Muñoz-Pedreros \& Yáñez 2009), reflejando una importante falta de información. Una de las especies que es asignada a Atacama es el quique, G. cuja, el que según Iriarte (2008) se encontraría en las altas montañas de esta región; sin embargo, Quintana et al. (2009) no la reconocen para esta región. Similar situación ocurre con $C$. laniger, de la cual las únicas localidades registradas en publicaciones científicas son la Reserva Nacional Las Chinchillas y La Higuera, al norte de la IV Región (Spotorno et al. 2004). En Atacama se registraron capturas a los alrededores de Vallenar por Wolffsohn (1921) pero actualmente no se conocen nuevos registros, sin embargo Iriarte (2008) extiende su rango de distribución para las altas cumbres de Copiapó, hasta 80 $\mathrm{km}$ al norte de Chañaral. Estas contradicciones se repiten con T. pallidor, T. brasilensis u H. montanus, L borealis, $L$. cinereus, M. chiloensis, L. jacobitus, L. colocolo, C. chinga y $C$. rex. Esto se debe en gran medida a que muchas de ellas no tienen registros de colectas en las colecciones referencia ni han sido objeto de investigaciones específicas. Por otro lado, se han registrado algunas especies en zonas aledañas a la Región de Atacama, pero de las que no se tiene certeza de su existencia en esta región, como $M$. coypus, A. longipilis, C. lepidus y $A$. cinerea.

Efectivamente, existe un bajo número de investigaciones y prospecciones de la fauna atacameña, y que queda de manifiesto en el escaso número de publicaciones científicas. Por ejemplo, hemos encontrado solo una publicación de murciélagos para Atacama, que registra la presencia de $M$. atacamensis en Caldera por Cabrera (1903). En términos de distribución y abundancia, podemos citar a Meserve \& Glanz (1978), que analizaron la relación de abundancia y microhábitat en roedores, y Samaniego \& Marquet (2009) para riqueza de especies de mamíferos y mariposas. Para estudios genéticos, las especies estudiadas han sido sólo Lama guanicoe, V. vicugna (Marín et al. 2007, Marín et al. 2008), O. degus (Valladares 2009) y A. olivaceus (RodríguezSerrano et al.2006). Cabe destacar que la mayor contribución al conocimiento de los mamíferos atacameños fue realizada en la primera mitad del siglo XX por Gigoux (1926, 1939) y Wolffsohn $(1916,1921)$. Distinta es la situación con los libros de divulgación científica, que si bien corresponden a documentos que sintetizan una importante cantidad de información, carecen de datos específicos de colectas de especimenes, y por lo tanto los rangos de distribución que se entregan no están necesariamente respaldados por datos concretos, cayendo en una serie de errores importantes (Teta \& D'Elia 2009).

En términos taxonómicos, hay algunas especies atacameñas que merecen especial atención, como por ejemplo, $E$. puerulus, que no es adscrito a Atacama por Iriarte (2008) y Muñoz-Pedreros \& Gil (2009). Sin embargo, se han realizado una serie de colectas de esta especie en los alrededores de Copiapó. Estas poblaciones se alejan a lo descrito previamente para E. puerulus, en el sentido que ésta última estaría restringida al altiplano de la Región de Antofagasta, por lo que creemos que se debe revisar la posición taxonómica de las poblaciones del valle de Copiapó. Por otro lado, la presencia de $A$. bennetti en el valle de Copiapó es un hallazgo importante en términos taxonómicos, pues observaciones preliminares de su morfología externa y coloración hacen suponer la existencia de una especie distinta a las de la zona central de Chile, y en ese caso se debería asignar a estatus específico a murrayi. Aún permanece incierta la posición taxonómica de las especies del género Lagidium, habiendo diferencias de criterio entre diversos autores (Wilson \& Reeder 2005, Iriarte 2008, Muñoz-Pedreros \& Gil 2009), por lo que no está clara la posición taxonómica de las poblaciones que habitan la Región de Atacama. 
En relación al estado de conservación que se les otorga a los mamíferos atacameños, se observan importantes incongruencias entre los listados de IUCN, SAG, CONAF e ICP. Sin embargo, dichas evaluaciones no reflejan necesariamente la real situación en Atacama, por ejemplo, O. degus es catalogado como "Preocupación Menor" por IUCN, y "Frágil" por el ICP, sin embargo, en Atacama se conoce sólo una pequeña población de esta especie, al parecer reducida a una quebrada en la Provincia de Huasco, por lo que a priori podríamos suponer que su estado de conservación a nivel local es "Crítico", ya que se encuentra en una zona de explotación agrícola. Un caso particularmente importante es el que ocurre con el guanaco, especie que ha disminuido sus poblaciones sostenidamente en Atacama, ya sea por la caza de perros asilvestrados, enfermedades parasitarias como la sarna, fragmentación del hábitat por carreteras, o caza por humanos. Sin embargo, para la IUCN se encuentra como "Preocupación Menor", pero para SAG y CONAF se encuentra "En Peligro" y por el ICP como "Vulnerable". Un factor que permite mantener cierta confianza es que esta especie se encuentra protegida en los tres parques nacionales de la región, aunque es importante analizar la información de los censos interanuales que desarrolla CONAF para saber la evolución de sus poblaciones y conocer la eficacia de su protección. V. vicugna es catalogada como "En Peligro" por el SAG y CONAF, destacándose esta última por haberla evaluada en la III Región. Sin embargo, la IUCN la cataloga como de "Preocupación Menor", sin embargo, esta poblaciones han comenzado a ser mermadas por epidemias de sarna, lo que las debilita y quedan expuestas a caza por depredadores (Moisés Grimberg comentario personal). Si bien el $79 \%$ de los mamíferos de Atacama se encuentran protegidos en alguna de las Áreas Silvestres Protegidas de la región, también hay que considerar que la presión antrópica sobre ellas ha aumentado, particularmente con el aumento sostenido de la agricultura y la minería.

Los análisis modernos del estado de conservación de las especies se están llevando a cabo por métodos más exactos y objetivos. Sin embargo, estos métodos tienen una debilidad en cuanto a la cantidad y calidad de la información con que se alimentan los algoritmos, los que al menos en Atacama son muy pobres, por ejemplo la falta de certeza de varias especies en la región, su distribución, abundancia local, presencia en las áreas silvestres protegidas, presión antrópicas sobre ellas, etc.

Efectivamente, la Región de Atacama es considerada una de las menos prospectadas en lo que concierne a mamíferos (José Yáñez, comentario personal). Un aspecto importante que refleja esta situación, además de la falta de publicaciones científicas, es el escaso material colectado en la Región de Atacama que se encuentra en las colecciones taxonómicas nacionales. Por ejemplo, en el Museo Nacional de Historia
Natural de Chile se encuentra solo un espécimen de $A$. olivaceus del 18 de Agosto de 1987 (MNHN 1401) colectado en Atacama, pero sin localidad exacta, y en la Colección de la Universidad Austral de Chile existen solo seis especimenes de $P$. darwini (IEEUACH 3267 - 3272). En colecciones internacionales, como el Museum of Southwestern Biology (MSB), Field Museum of Natural History (FMNH), y Museum of Vertebrate Zoology of the University of California at Berkeley (MVZ), se encuentra un mayor número de especimenes de la región, pero aún insuficiente. Pero más grave aún es la falta de colecciones taxonómicas de referencia en Chile, y su completa ausencia el norte del país.

En relación a las características ecológicas, hemos podido evidenciar una zona de alta diversidad de mamíferos en Atacama, elque correspondería a lazona del cordón montañoso costero y valles centrales (Figura 1). Esto demuestra que la mayor parte de las especies se encuentra en zonas bajas, con vegetación xerofítica arbustiva, con predominancia de cactáceas. Estos sectores corresponden a las zonas costeras de las provincias de Huasco y Copiapó, las que se caracterizan por presentar ríos y humedales. También es una zona de alta influencia de humedad provocada por neblina, así como por efectos esporádicos de ENSO, correspondiendo a valles de vegetación azonal, con matorral ripario. De acuerdo a Ulloa \& Ortiz de Zarate (1989), en esta zona se encuentra el límite norte del sistema de valles transversales, que se desarrolla por medio de cordones montañosos que interconectan Los Andes con la Cordillera de la Costa. Por lo tanto, Atacama se divide en dos áreas pluviométricas en los $27^{\circ} \mathrm{S}$, al norte con muy escasas precipitaciones, y al sur con débiles lluvias, donde aparecen los dos ríos pluvionivales, el río Copiapó y el Huasco.

La alta montaña atacameña, que considera la cordillera de Domeyko, altiplano y cordillera de Los Andes, ha sido muy poco explorada, particularmente en la Provincia de Chañaral. Las zonas de alta exploración han correspondido a zonas de explotación minera, y que corresponden a estudios ambientales de línea base, que por lo general no tienen rigor científico y gran parte de sus resultados no llegan a ser publicados en revistas científicas. En estas zonas pueden llegar a encontrase una alta riqueza de especies, pero al no ser depositadas en colecciones de referencia, o analizadas por especialistas, quedan sin ser utilizadas en los listados de biodiversidad.

Queda, por lo tanto, mucho que prospectar, recolectar, analizar y evaluar en torno a la riqueza de especies de mamíferos en la Región de Atacama, convirtiéndose ésta en una de las menos conocidas de Chile, por lo que no será de extrañar que se tenga que modificar este listado preliminar de especies y sus estados de conservación con criterios locales. 

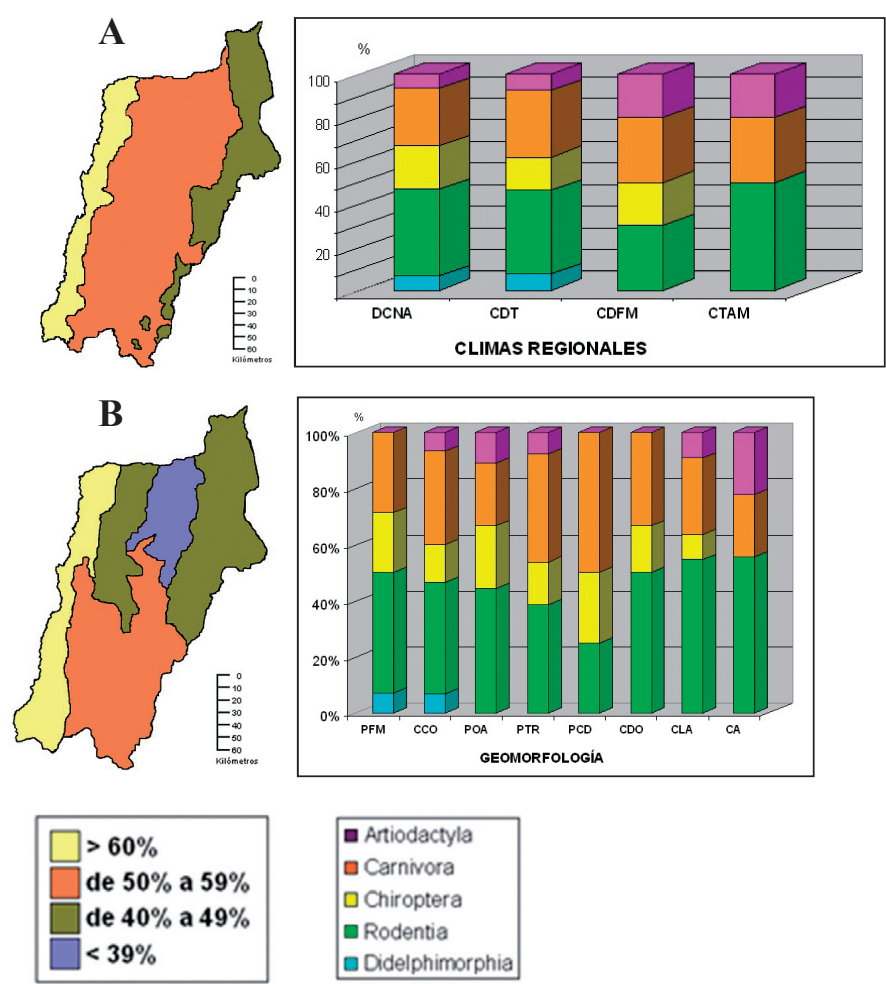

aDidelphimorphia
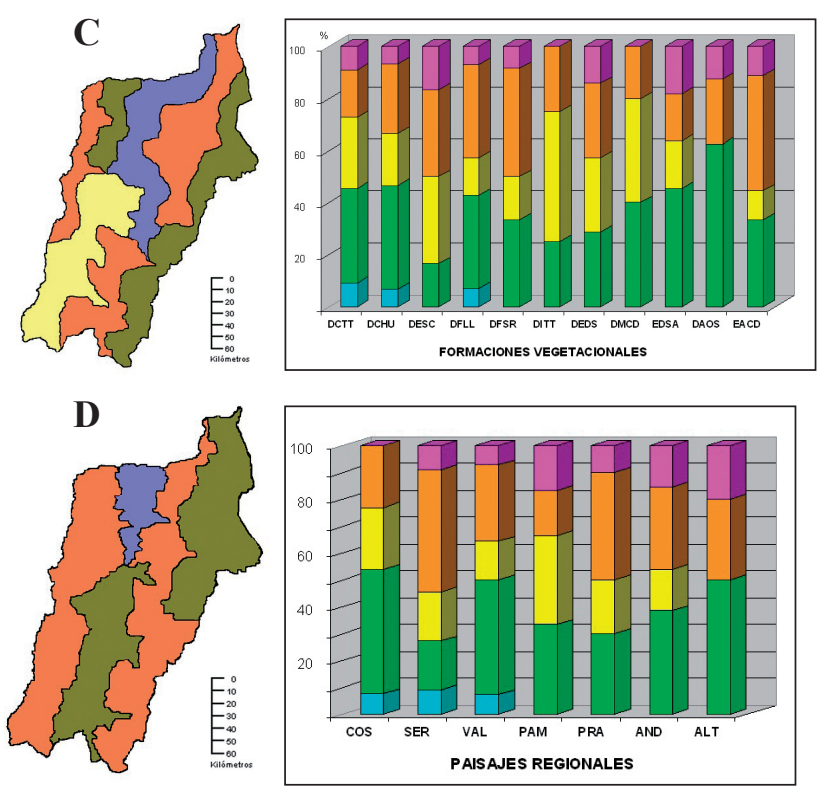

Figura 1. Riqueza de especies de mamíferos en la Región de Atacama. En mapas se observan zonas ecológicas con distintos niveles de riqueza de especies y en gráficos se muestra el porcentaje de mamíferos por familia (solo las 24 especies confirmadas para Atacama). (A) Climas Regionales: DCNA: Desierto Costero con Nubosidad Abundante, CDT: Clima Desértico Transicional, CDFM: Clima de Desierto Frío de Montaña, CTAM: Clima de Tundra de Alta Montaña. (B) Formaciones Vegetacionales: DCTT: Desierto Costero de Taltal, DCHU: Desierto Costero de Huasco, DESC: Desierto Estepario de Sierras Costeras, DFLL: Desierto Florido de los Llanos, DFSR: Desierto Florido de las Serranías, DITT: Desierto Interior de Taltal, DEDS: Desierto Estepario del Salvador, DMCD: Desierto Montano de la Cordillera de Domeyko, EDSA: Estepa Desértica de Salares Andinos, DAOS: Desierto Altoandino de Ojos del Salado, EACD: Estepa Altoandina de la Cordillera de Doñana. (C) Geomorfologia: PFM: Planicies Fluviométricas, CCO: Cordillera de la Costa, POA: Pampa Ondulada Austral, PTR: Pampa Transicional, PCD: Precordillera de Domeyko, CDO: Cordillera de Domeyko, CLA: Cordillera de Los Andes, CA: Cuenca Altiplánica. (D) Paisajes Ecogeográficos: COS: Costero, SER: Serrano, VAL: Valle, PAM: Pampeano, PRA: Preandino, AND: Andino, ALT: Altiplánico.

Figure 1. Species richness of mammal's of the Atacama region. Maps show ecological zone with different levels of species richness and graphs show the percentage of mammals species by families (only 24 confirmed species for Atacama region). (A) Regional climates: DCNA: Coastal desert with abundant clouds, CDT: Transitional desert climate, CDFM: Climate of cold desert mountain, CTAM: Climate of high mountain Tundra. (B) Vegetation formations: DCTT: Taltal coastal desert, DCHU: Huasco coastal desert, DESC: Steppe desert of coastal mountain, DFLL: Desert in blooms of plains, DFSR: Desert in blooms of mountains, DITT: Interior desert of Taltal, DEDS: Steppe desert of El Salvador, DMCD: Mountain desert of the Cordillera de Domeyko, EDSA: Steppe desert of Andean salt flat, DAOS: High Andean desert of Ojos del Salado, EACD: High andean steppes of the Cordillera de Doñana. (C) Geomorphology: PFM: Fluviometric plains, CCO: Coastal range, POA: Austral wavy pampas, PTR: Transitional pampas, PCD: Domeyko foothills, CDO: Cordillera de Domeyko, CLA: Cordillera de Los Andes, CA: Plateu basin. (D) Ecogeographic landscape: COS: Coastal, SER: Mountain, VAL: Valley, PAM: Pampa, PRA: Pre-Andean, AND: Andean, ALT: Plateu.

\section{AGRADECIMIENTOS}

Agradezco a Gerardo Jara de la Secretaría Ministerial del Medio Ambiente de Atacama, Moisés Grimberg de la Corporación Nacional Forestal (CONAF) de Atacama y Martin Espinosa (Universidad Mayor) por compartir información muy relevante sobre los mamíferos de Atacama. A Guillermo D'Elia, de la Universidad Austral de Chile,
Ángel Spotorno, de la Universidad de Chile, y José Yáñez, del Museo de Historia Natural de Chile, por enviarme información de mamíferos atacameños de sus respectivas colecciones. A Wilfredo Briones de la I. Municipalidad de Diego de Almagro por compartir información de mamíferos de la Provincia de Chañaral. A Rosa Soto (CRIDESAT) por la información de las formaciones vegetacionales de Atacama. Al Servicio Agrícola y Ganadero por la autorización $N^{\circ}$ 
4664 para captura de roedores en Atacama. Este trabajo es financiado por el Centro Regional de Investigación y Desarrollo Sustentable de Atacama (CRIDESAT) y a la Compañía Minera Lobo Marte S. A.

\section{LITERATURA CITADA}

Braun, J.K.; Mares, M.A. 2002. Systematics of the Abrocoma cinerea species complex (Rodentia: Abrocomidae), with a description of a new species of Abrocoma. Journal of Mammlogy 83(1): 1-19.

Cabrera, A. 1903. Catálogo descriptivo de los Quirópteros chilenos. Revista Chilena de Historia Natural 7 (5-6): 278 -308 .

Cofré, H. \& Marquet, P. 1999. Conservation status, rarity, and geographic priorities for conservation of Chilean mammals: an assessment. Biological Conservation 88(1): 53-68.

Corporación Nacional Forestal. 1993. Libro Rojo de los Vertebrados Terrestres de Chile. Actas Simposio "Estado de la conservación de la Fauna de Vertebrados Terrestres de Chile". 2da edición. 65 pp.

Corporación Nacional Forestal. 1997a. Plan de Manejo "Parque Nacional Llanos de Challe". Documento de Trabajo $N^{\circ}$ 250, $129 \mathrm{pp}$.

Corporación Nacional Forestal. 1997b. Plan de Manejo "Parque Nacional Nevado Tres Cruces". Documento de Trabajo $N^{\circ}$ 255, 117 pp.

Corporación Nacional Forestal. 2002. Plan de Manejo "Parque Nacional Pan de Azúcar”. Documento de Trabajo N 373, $185 \mathrm{pp}$.

Currier, M.J. 1983. Felis concolor. Mammalian Species 200: 1 $-7$.

Elgueta, E., Reid, S., Pliscoff, P., Méndez, M.A., Núnez J. \& Smith-RAmírez, C. 2006. Catastro de vertebrados terrestres y análisis en seis hábitats presentes en la Reserva Nacional Futaleufu, Provincia de Palena, X Región, Chile. Gayana 70 (2): $195-205$.

Franklin, W.L., Johnson, W.E., Sarno, R.J. \& Iriarte, J.A. 1999. Ecology of the Patagonia puma Felis concolor patagonica in southern Chile. Biological Conservation 90: 33 - 40.

Gajardo, R. 1994. La vegetación natural de Chile. Clasificación y distribución geográfica. Editorial Universitaria, Santiago, Chile. 165 p.

Galaz, J.L. \& Yañez, J. 2006. Los Murciélagos de Chile: Guía para su reconocimiento. Ediciones del Centro de Ecología Aplicada. Santiago, Chile. 80 pp.

Galaz, JL., Yañez, J., Gantz, A. \& Martinez, R. 2009. Orden Chiroptera. En Mamíferos de Chile. (Eds. Muñoz-Pedreros \& Yáñez). Pag. $67-83$.

Gigoux, E.E. 1926. La Quebrada del León (Caldera). Revista Chilena de Historia Natural 30(1): 288 - 297.

Gigoux, E.E. 1939. La Travesía. Revista Chilena de Historia Natural 43(1): 17 - 20. 213 pp.

González, B.A., Palma, R.E., Zapata, B. \& Marín J.C. 2006. Taxonomic and biogeographical status of guanaco Lama guanicoe (Artiodactyla, Camelidae). Mammal Review 36(2): 157-178.

GraU, J. 1986. La Chinchilla. Su crianza en todos los climas. 3ra edición. El Ateneo, Buenos Aires. 213 pp.

Grimberg, M., Valladares, P., Cáceres, P. \& Briones, W. 2011. Distribución del Puma concolor (Linneaus, 1771) en la Región de Atacama. Boletín del Museo Regional de Atacama (En Prensa).

Iriarte, JA. 2008. Mamíferos de Chile. Lynx Ediciones, 420 pps. International Union For Conservation Of Nature (Iucn). 2011. IUCN Red List of Threatened Species. Version 2011.1. (http://www.iucnredlist.org).

Juliá C., Montecinos, S., \& Maldonado, A. 2008. Características climáticas de la Región de Atacama. En Libro Rojo de la Flora Nativa y de Los Sitios Prioritarios para su Conservación: Región de Atacama (Eds. Squeo, F.A., Arancio, G. \& Gutiérrez, J.R.) Ediciones Universidad de La Serena, La Serena, Chile. 3: 25-42.

Köppen, W. 1948. Climatología. Fondo de Cultura Económica, México. 1a Ed., 478 pp.

ManN, G. 1978. Los pequeños mamíferos de Chile. Marsupiales, quirópteros, edentados y roedores. Gayana 40: 1-342.

Marín, J.C., Zapata, B., Gonzalez, B., Bonacic, C., Wheeler, J.C., Casey, C., Bruford, M.W., Palma, E., Poulin, E., Alliende, M.A., \& Spotorno, A. 2007. Systematics, taxonomy and domestication of alpaca and llama: new chromosomal and molecular evidence. Revista Chilena de Historia Natural 80(2): 121-140.

Marín, J.C., Spotorno, A., Gonzalez, B., Bonacic, C., Wheeler, J.C., Casey, C., Bruford, M.W., Palma, E. \& Poulin, E. 2008. Mitochondrial DNA variation and systematics of the guanaco (Lama guanicoe, Artiodactyla : Camelidae). Journal of Mammalogy 89(2): 269-281.

Meserve, P.L. \& Glanz, W.E. 1978. Geographical ecology of small mammals in the northern Chilean arid zone. Journal of Biogeography 5: $135-148$.

Meynard, A.P., Palma, R.E. \& Rivera-milla, E. 2002. Phylogeographic relationships of the Chilean llacas of the genus Thylamys (Marsupialia, Didelphidae) based on sequences of the cytochrome $b$ mitochondrial gene. Revista Chilena de Historia Natural 75(2): 299-306.

MolinA, J.I. 1782. Saggio sulla Storia Naturale del Chili di Gio. Fratell: Masie, Bologne, 308 pp.

Muñoz-Pedreros, A. \& Gil, C. 2009. Orden Rodentia. En Mamíferos de Chile (Eds. Muñoz-Pedreros \& Yáñez). Pag. 93-57.

Novoa J.E., Tracol, Y. \& LóPez, D. 2008. Paisajes eco-geográficos de la Región de Atacama. En Libro Rojo de la Flora Nativa y de Los Sitios Prioritarios para su Conservación: Región de Atacama (Eds. Squeo, F.A., Arancio, G. \& Gutiérrez, J.R.) Ediciones Universidad de La Serena, La Serena, Chile. 2: 13-24.

OsGood, W.H. 1943. The Mammals of Chile. Field Museum of Natural History. Zoological Series 30: 1-268.

Palma, R.E. 1995. Range expansion of two South American mouse opossums (Thylamys, Didelphidae) and their biogeographic implications. Revista Chilena de Historia Natural 68(4): 515-522.

Palma, R.E. 1997. Thylamys elegans. Mammalian Species 572: $1-4$.

Phillipi, R.A. 1901. Nueva especie chilena de zorras. Anales de la Universidad de Chile 108: 167-170.

Porter, C. 1899. Datos para la Fauna i Flora de la Provincia de 
Atacama. Revista Chilena de Historia Natural 3(1-2): 179182.

Quintana, V., Yañez, J., Valdebenito, M. \& Iriarte, J.A. 2009. Orden Carnívora. En Mamíferos de Chile. (Eds. MuñozPedreros \& Yáñez). Pag. 193-230.

RAU, J.R. 2005. Biodiversidad y colecciones científicas. Revista Chilena de Historia Natural 78: 341-342.

Rodriguez-Serrano, E., Cancino, R.A. \& Palma, R.E. 2006. Molecular phylogeography of Abrothrix olivaceus (Rodentia: Sigmodontinae) in Chile. Journal of Mammalogy 87(5): 971 -980.

Servicio Agrícola y Ganadero (SAG). Reglamento de la Ley de Caza D.S N ${ }^{\circ} 5$ / 1998 con modificaciones introducidas por el D.S N 53 / 2004.

Samaniego, H. \& Marquet, P. 2009. Mammal and Butterfly species richness in Chile: taxonomic covariation and history. Revista Chilena de Historia Natural 82: 135-151.

Silva-Aranguiz, E. 2011. Recopilación de la literatura sobre roedores y marsupiales chilenos desde 1780 hasta 2011. Recopilación de la literatura sobre Chiroptera y Xenarthra en Chile desde 1780 hasta 2011. Recopilación de la literatura sobre Carnívoros de Chile desde 1780 hasta 2011. Recopilación de la literatura sobre ungulados en Chile desde 1780 hasta 2011. Centro de Investigación Avanzada en Ecología y Biodiversidad, Departamento de Ecología, Pontificia Universidad Católica de Chile. http://www.bio. puc.cl/auco/artic04/micromam.htm.

Simonetti, J.A., Arroyo, M.T.K., Spotorno, A.E. \& Lozada, E. 1995. Diversidad biológica en Chile. Comisión Nacional de Ciencia y Tecnología, Santiago, Chile. 364 pp.

SimonetTi, J.A. 1999. Diversity and conservation of terrestrial vertebrates in mediterranean Chile. Revista Chilena de Historia Natural 72: 493-500.

Spotorno, A.E., Valladares, P., Marin, J.C., Palma, E., \& Zuleta, C. 2004. Molecular divergence and phylogenetic relationship among chinchillid species (Rodentia: Chinchillidae). Journal of Mammalogy 85: 384 - 388.

Squeo, F.A., Gutierrez, J.R., \& Hernández, I.R. 2004. Historia Natural del Parque Nacional Bosque Fray Jorge. Ediciones Universidad de La Serena, La Serena, xii + 319 pp.

Steppan, S.J., Ramirez, O., Banbury, J., Huchon, D., Pacheco, V., Walker, L., Spotorno, A. 2007. A molecular reappraisal of the systematics of leaf-eared mice Phyllotis and their relatives. Pp. 799-826 In The Quitessential Naturalist: Honoring the Life and Legacy of Oliver P. Pearson (Eds. Kelt,
D.A., E.P. Lessa, J. Salazar-Bravo \& J.L. Patton) University of California Publications in Zoology 134: 1-981.

Tamayo, M. 2009. Orden Xenarthra. En Mamíferos de Chile. (Eds. Muñoz-Pedreros \& Yáñez). Pag. 85-92.

Tamayo, M. \& Frassinetti, D. 1980. Catálogo de los mamíferos fósiles y vivientes de Chile. Boletín del Museo Nacional de Historia Natural de Chile 37: 323-399.

Teta, P. \& D'elia, G. 2009. Mamíferos de Chile. A. Iriarte Walton. 2008. Lynx Ediciones, Barcelona, España, 420 pp. Mastozoología Neotropical 16(2): 528-531.

Ulloa, R. \& Ortiz De Zarate, P. 1989. Geografía de la III Región de Atacama. Colección Geográfica de Chile, Ediciones Instituto Geográfico Militar, Santiago, 206 pp.

Valladares, P. 2002. Divergencia Molecular de las Especies Silvestres y Cepas Domesticadas del Género Chinchilla. Mastozoología Neotropical 9 (1): 96-98.

Valladares, P. 2009. Variación geográfica de la conducta antidepredatoria del Octodon degus (Molina 1782) bajo un contexto filogeográfico. Tesis para optar al grado de Doctor en Ciencias Biomédicas, Facultad de Medicina de la Universidad de Chile.

Valladares, P. 2011. Análisis, síntesis y evaluación de la información científica de los lagartos de la Región de Atacama. Gayana 75(1): 81-98.

Valladares, P, Espinoza, M., Torres, M., Díaz, E., Zeller, N., De La Riva, J., Grimberg, M. \& Spotorno, A. 2012. Nuevo registro de Chinchilla chinchilla (Rodentia, Chinchillidae) para la Región de Atacama. Extensión de su rango de distribución y estado de conservación. Mastozoología Neotropical (Argentina) En Prensa.

Villalobos, R. 2008. Hábitos predatorios del puma (Puma concolor) y su impacto en la ganadería de la Provincia de Parinacota, Región de Arica y Parinacota, Chile. Tesis para optar al título de Médico Veterinario de la Universidad de Chile. 68 pp.

Wilson, D.E. \& ReEder, D.A.M. (Editors). 2005. Mammal Species of the World. A Taxonomic and Geographic Reference (3rd ed), Johns Hopkins University Press, 2142 pp.

Wolffsohn, J.A. 1916. Description of a new rodent from Central Chile. Revista Chilena de Historia Natural 20: 6-7.

Wolffsohn, J.A. 1921. Catálogo de cráneos de Mamíferos de Chile colectados entre los años 1896 y 1918. Revista Chilena de Historia Natural 25(1): 511-529.

Wolffsohn, J.A. 1923. Medidas máximas y mínimas de algunos mamíferos chilenos colectados entre los años 1896 y 1917. Revista Chilena de Historia Natural 27(1): 159-167.

Recibido: 26.09.11

Aceptado: 01.03.12 